\title{
AC 2011-465: COLLABORATIVE INFORMATION BEHAVIOUR OF EN- GINEERING STUDENTS IN A SENIOR DESIGN GROUP PROJECT: A PILOT STUDY
}

\section{Nasser Saleh, Queen's University}

Nasser Saleh is Associate Librarian and the Integrated Learning Librarian at Queen's University Engineering and Science Library. He received a Bachelor's Degree (Hons.) in Electrical Engineering (University of Khartoum), a Master's Degree in Telecommunications and Networks Management (Syracuse University), and a Master's Degree in Library and Information Science (Syracuse University) and he is currently a PhD Candidate in Information Studies at McGill University researching Collaborative Information Behaviour of Undergraduate Engineering Students. Nasser is actively involved with integrating information literacy skills in undergraduate engineering courses at Queen's University. 


\title{
Collaborative Information Behaviour of Engineering Students in a Senior Design Group Project: a Pilot Study
}

\begin{abstract}
This paper presents a pilot study of an ongoing research conducted by an Engineering Librarian investigating the collaborative information behaviour of undergraduate engineering students who are working on a course-based engineering project. The research aims to understand how students collaboratively identify their information needs and then seek and use information sources from different channels as a group. The study plans to analyse the interaction of the project as the learning with learners' information-related activities as students try to identify their information needs, seek information, and then use information for their project during a groupbased course. The paper represents the first case study where data were collected through a webbased survey at the end of a senior multidisciplinary design engineering course along with a preliminary descriptive analysis of the collected data that are related to the practice of both academic engineering librarians and engineering educators who are involved in these courses.
\end{abstract}

Introduction

Information seeking is an important and integrated part of work domains and work practices, and it has been the focus of many research studies in information science. While many different models of information seeking have been proposed, they mostly assume that the information seeker is an individual interacting with complex information spaces. Recent research has found that people frequently collaborate and communicate when they retrieve and use information, and researchers have begun to challenge the individualistic approach by exploring the social, contextual, and collaborative dimensions of information seeking.

A large volume of research tried to explore the information behaviour of engineers as professional knowledge workers. A recent questionnaire-based study found out that design engineers spend $21 \%$ of their time searching for and absorbing information ${ }^{1}$. Thus, as engineering is an information-intensive domain, many of the new engineering competencies as required by accreditation boards for engineering programs, such as Accreditation Board for Engineering and Technology (ABET) ${ }^{2}$ and the Canadian Engineering Accreditation Board $(\mathrm{CEAB})^{3}$, have challenged the existing, traditional, educational lecture-based approaches by introducing more courses that are designed as project-based learning courses in engineering programs within specific expected graduating attributes. The transition from strictly traditional approaches in engineering education represents significant opportunities for change by implementing project-based learning to create a learning environment to provide students with the possibility of achieving sustainable and transferable skills, while at the same time exposing them to the complexities of work related issues ${ }^{4}$.

Although both ABET outcomes and CEAB graduate criteria did not explicitly mention information literacy skills as a graduate attribute, it has been anticipated that information literacy skills are embedded within these different engineering graduate attributes ${ }^{5}$ by mapping information literacy standards such as the Association of College and Research Libraries (ACRL) Information Literacy Competency Standards for Higher Education ${ }^{6}$ to some specific 
graduate attributes such as design and lifelong learning. Understanding information behaviour of students can be seen critical for developing information literacy skills of engineering students. The relationship between research in information behaviour and information literacy has been highlighted in many recent research studies arguing that an understanding of information literacy would benefit from being based on an understanding of information seeking and that "information seeking and information literacy are two sides of the same coin"?

\section{Collaborative information behaviour}

Collaborative information behaviour has been defined as "the activities that a group or a team of people undertakes to identify and resolve a shared information need" ${ }^{8}$. This definition implies that collaborative activities are different from individual ones as they include communicating about the information need, sharing the retrieved information within the team, and coordinating the constituent information retrieval activities across multiple participants.

Another study has defined collaborative information behaviour as "an information access activity related to a specific problem solving activity that, implicitly or explicitly, involves human beings interacting with other human(s) directly and/or through texts (e.g., documents, notes, figures) as information sources in an work task related information seeking and retrieval process either in a specific workplace setting or in a more open community or environment"'. In the same study, the authors explained that this definition should be seen as a preliminarily definition that needs more refining through further studies, observations and investigations.

This study follows the definition of collaborative information behaviour as "collaborative information behaviour can be broadly defined as an activity where two or more actors communicate to identify information for accomplishing a task or solving a problem. .. [it] includes processes of problem identification, analysis of information need, query formulation, retrieval interactions, evaluation, presentation of results, and applying results to resolve an information problem" ${ }^{10}$. This definition was selected as it directly relates the task to the information behaviour of users and describes information-related activities as dynamic ones that are dependent on the assigned task and its complexity.

Engineering students, particularly in design engineering courses, are expected to work as a group to solve an engineering problem. The design problem is designed and evaluated in many ways that all students will work collaboratively as a group to solve the problem and provide a possible design through acquiring and using different types of information during all the project stages.

Research design

The design of the study is based on a qualitative and longitudinal research approach that is concerned with an understanding of the group members' experience during the project. The research method is a multi-method approach that includes a questionnaire and set of interviews to collect data on complex phenomena as each individual method would deliver only partial evidence on the phenomena, the multiple methods is expected to cover multiple aspects of students' experience. 
The research was designed to examine collaborative information behaviour in a naturalistic educational setting to gain more understanding of how students collaboratively seek information in an academic course and how students' information behaviours are affected by the learning task and its perceived complexity guided by the main research questions:

1- What are the collaborative information-related activities that engineering students encounter during a senior design course?

2- How does students' information behaviour interact with their underlying conceptions of the project learning task and its complexity in a project-based engineering course?

3- What is the effect of library instruction and collection on students 'collaborative information behaviour?

The research questions stem from a deep interest in how undergraduate engineering students seek information, formally or informally while working as a group in a senior engineering design course. It is also planned to explore how the nature of the required information for their project affects their information seeking, searching and use as they consult different resources that can be documentary or human. The situation of a design project group makes the research more focused on groups but individual information seeking will be touched on as well. The main focus of this research is within the role of the group as showed in Figure 1.

Figure 1. Research concept map

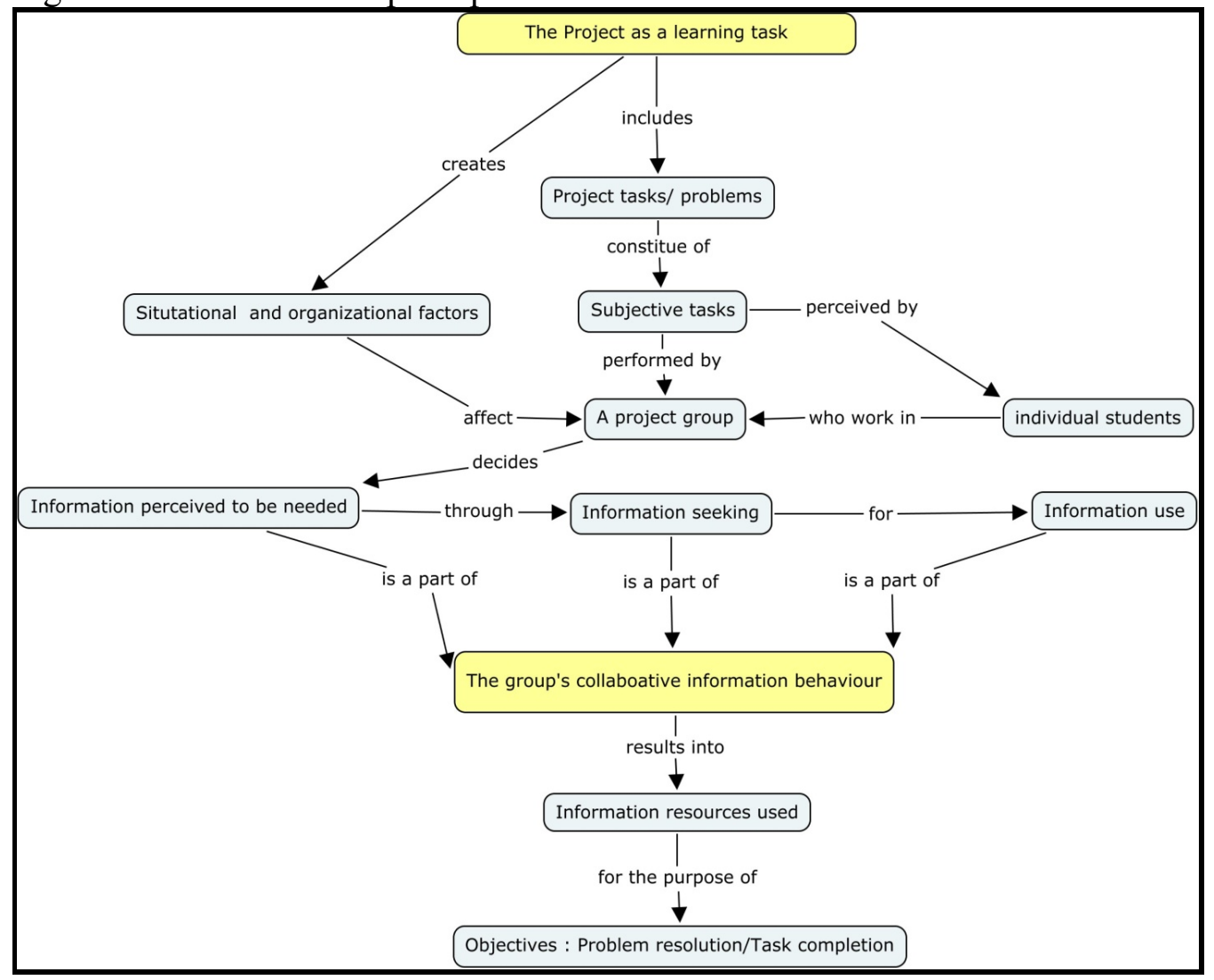


Pilot study design

A pilot study was conducted in March 2010 to collect data on students' experience in the design course and how the project task interacted with the group's collaborative information needs, seeking, and use. The pilot study did not aim to ask students about the information-seeking process in detail but it did try to capture the relationship between project task and students' collaborative information behaviour.

A web- based questionnaire of 33 questions was sent to students near the end of the academic year 2009/10, at the end of the project that took 8 months to accomplish in the final year capstone design course to get feedback about their experience of collaborative information behaviour in the project. The selected class comprised 63 students divided into 20 project groups.

The questionnaire had two parts that measured the perceived learning task complexity and the collaborative information behaviour from the students' point of view. Many questions were open ended to allow students to think aloud about their experience in addition to questions that indicate their level of agreement using Lickert scale concerning a number of statements about the project topic and their information behaviour. The questionnaire was available to students for 3 weeks and to be completed individually. Replies were grouped together by the project number for intra-group analysis. The following sections of this paper will present a partial analysis of the pilot study results and draw conclusions from them.

\section{Data preparation}

Project numbers were first coded randomly with characters depending on the number of respondents within each specific group. Each project is assigned to a character from $\mathrm{A}$ to $\mathrm{T}$ and respondents were assigned to numerical codes that represent their project, so respondents were identified as A1,B3, E4 .. etc.

The response rate to the survey was $66 \%$ from 42 students representing the 20 project groups. The number of respondents who belong to the same project group varies as shown in Table 2.

Table 1. Project assignment of the survey respondents

\begin{tabular}{|l|l|l|l|}
\hline Project\# & $\begin{array}{l}\text { No. of respondents } \\
\text { per project }\end{array}$ & No. of groups & Subtotal of respondents \\
\hline E & 4 & 1 & 4 \\
\hline A, B, C, D, F, G & 3 & 6 & 18 \\
\hline H, I, J, K, L, M, N & 2 & 7 & 14 \\
\hline O, P, Q, R, S, T & 1 & 6 & 6 \\
\hline Total
\end{tabular}

Respondents are from different engineering departments who work on a multidisciplinary project topic. Respondents were asked to identify their department in the second question. The majority of respondents were from Mechanical Engineering then followed by Chemical Engineering as shown in Table 2. 
Table 2. Department affiliation of the survey respondents

\begin{tabular}{|l|l|}
\hline Department & No. of respondents \\
\hline Mechanical Engineering & 19 \\
\hline Chemical Engineering & 13 \\
\hline Engineering Physics & 5 \\
\hline Applied Mathematics & 2 \\
\hline Civil Engineering & 2 \\
\hline Electrical Engineering & 1 \\
\hline
\end{tabular}

Preliminary data analysis

The questionnaire started with a numbers of statements that were based on the reviewed literature and the selected theoretical framework for this study. Relevant statements are used to examine both the dimensions of the project as the learning task and information-related activities of the group. The statements served as a point of departure for the study, so the purpose of using them in this study was to elaborate them during the research rather than testing them as hypotheses.

The purpose of the preliminary analysis for the questionnaire data is to define the variables and their association and also indicators to capture abstract concepts of the relationship between the learning task and students' information behaviour. The preliminary data analysis is a univariate analysis that is selected for two reasons: to get informative descriptive statistics about tendencies in students' responses, and to enable the researcher to determine what types of bivariate or multivariate procedure will be used in more advanced analyses of data by knowing the characteristics of individual variables and indicators.

The descriptive analysis of students' responses to the agreement questions, students were asked to give an answer about their level of agreement on the scale 1-5, where 1 is lowest (strongly disagree) and 5 is highest (strongly agree). The purpose of representing these descriptive data is to show the tendencies that occurred during the course. Detailed analysis of these finding will be continued with the qualitative analysis of open ended questions that will be analysed in a later stage of the research. The following sections will include tabulated descriptive statistics, the level of agreement is shown as: SA, A, N, D, and SD representing strongly agree, agree, neither agree/disagree, disagree, or strongly disagree respectively.

Task assignment

The first 3 survey statements were about students' interest in their selected projects, the project topic's clarity, and the students' prior knowledge at the beginning of the project. 
Figure 2. Students' perceptions to task assignment

At the beginning of the project, I felt that the project topic was clear to me and I could easily find the needed background information.

At the beginning of the project, I felt that I had prior knowledge about the project topic.

I had an interest in the project topic before I was assigned to it.

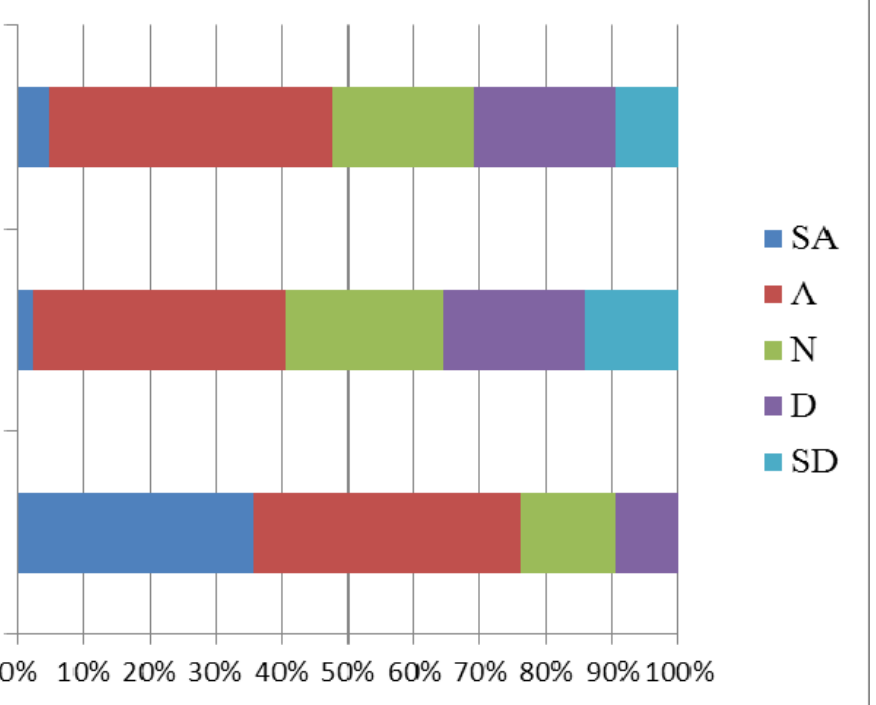

Finding information and task formulation

Students were asked about how they perceive the process of finding relevant information for their projects and whether this process has been improved with more understanding of the project's topic. The results show that most students agree with the positive impact of task understanding on finding the information that they can use for their project. Students were also asked if finding and using information was an ongoing activity during the project, the responses show that the level of students' agreement to the statement is relatively high. Students were finally asked if they have to use different information sources and their responses show a high level of agreement as shown in Figure 3.

Figure 3. Students' perceptions to information search as a project activity

The nature of my project required me to look for relevant information from many different sources

Finding and using information for my project was an ongoing activity.

Finding relevant information for my project improved with my understanding of the project scope.

Finding relevant information for my project has been an easy process.

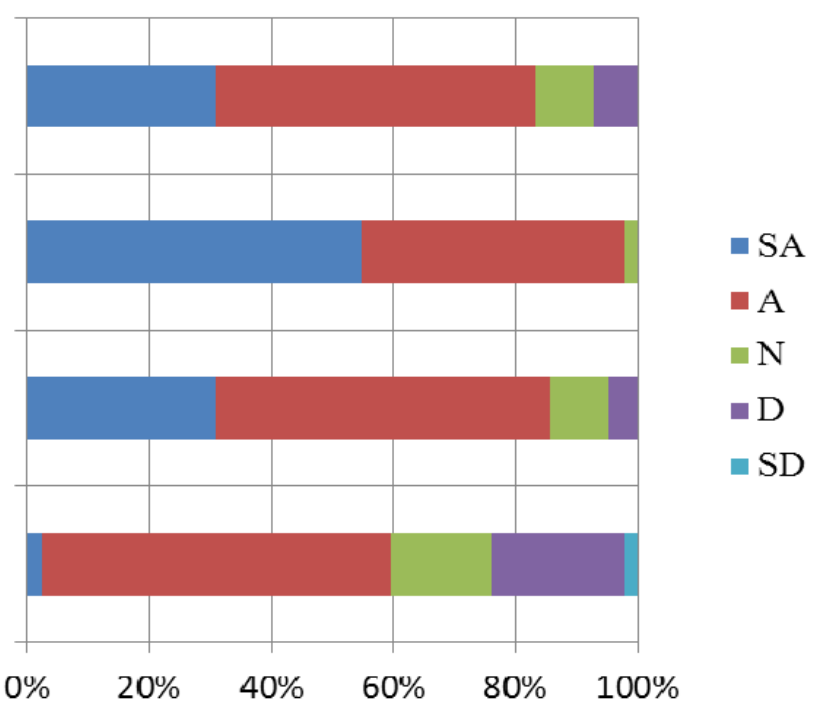




\section{Collaborative information activities}

Students were asked if they looked for information as individuals or by working as a group, the responses showed the most students experienced it individually and a group. Students were then asked about the reason to look for information collaboratively by giving their agreement to 5 statements that describe different contextual factors as shown in Figure 4. As the results show that complexity of the project task was seen to be a reason for students to collaboratively seek information and also access to information sources was also a motivation for collaborative activities.

Figure 4. The reason of collaborative information activities

The needed information requires searching expertise that I do not have as an individual

It is easier to look for information as a group rather than as an individual

The needed information was not available to any of us as individuals

The information needed for the project is complex

It is a requirement for this course to work as a team

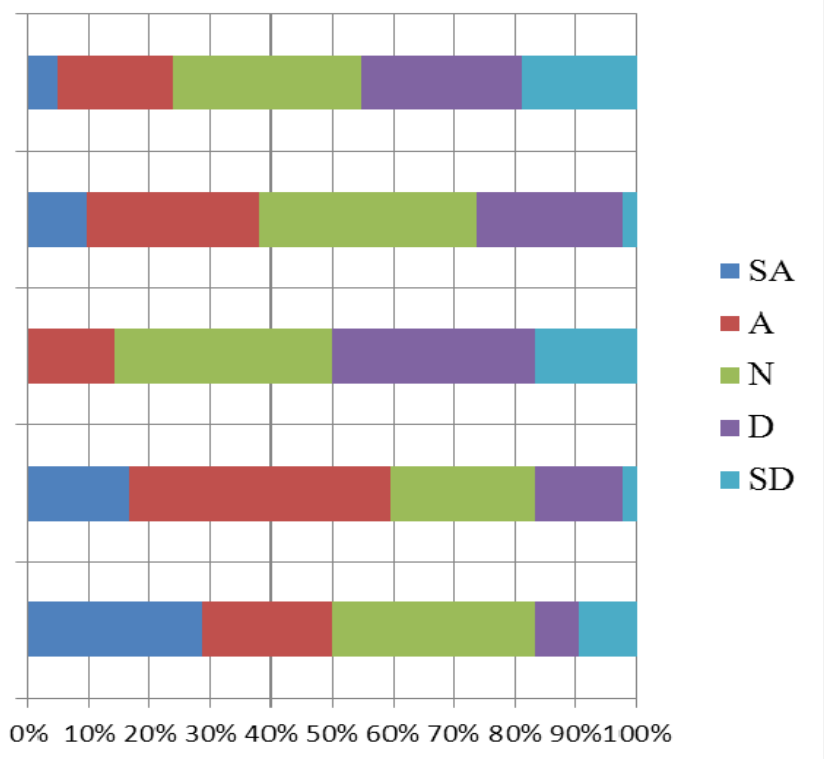

Students were asked about the outcomes of their collaborative information activities if they were able to find what they were seeking. Most students have agreed that the outcomes of collaborative activities have been positive as shown in Figure 5.

Figure 5. Outcomes of collaborative information activities

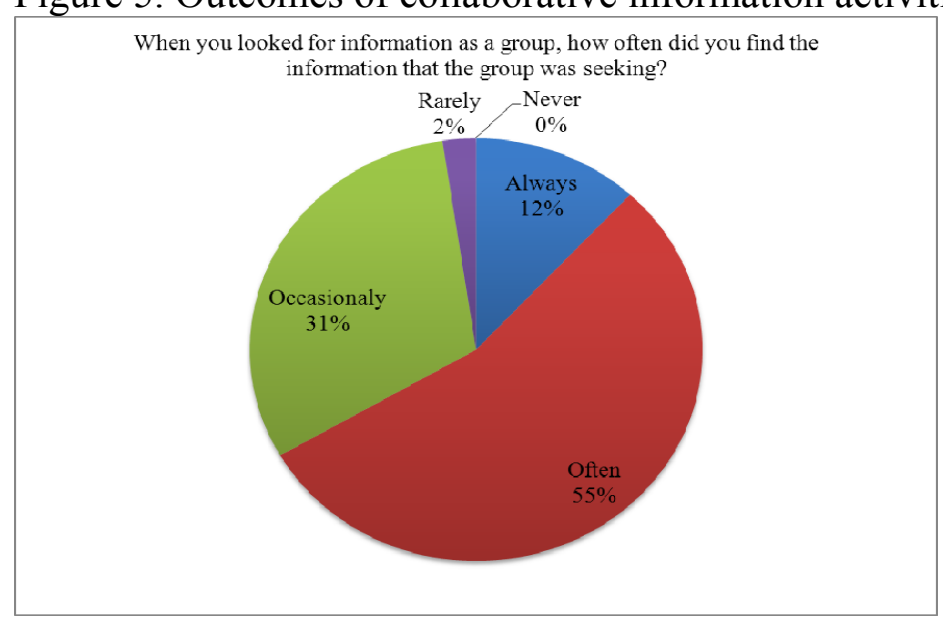


Types of documentary information sources

Students were asked to identify the types of information sources they have used for their projects and to select all the type of information sources they have used. The selected information sources are available from different channels as this meets the justification of engineering as an information-intensive field that require finding and using information that are not necessarily available through one definite channel. The results also show an evidence of the diversity of information sources that students had to use during their project as shown in Figure 6. Other information sources included "asking experts", "help from the course instructor", and "phone calls with the project client".

Figure 6. Used information sources

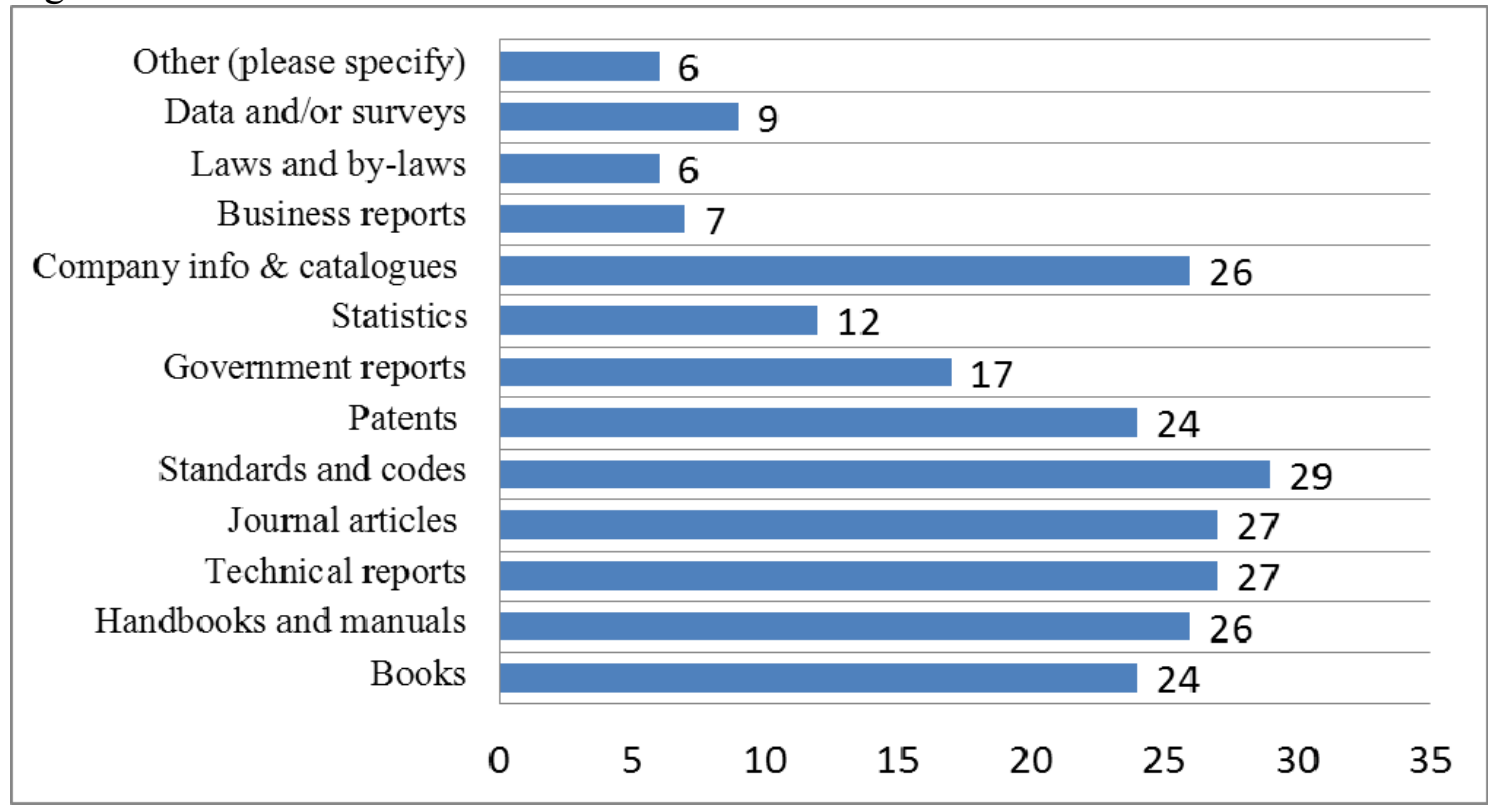

Students were also asked about the tools that they have used during their collaborative information-related activities. The results showed that the use of email as the main channel they used followed by face to face meetings, other tools have been also used as shown in Figure 7.

Figure 7. Used tools for collaborative information activities

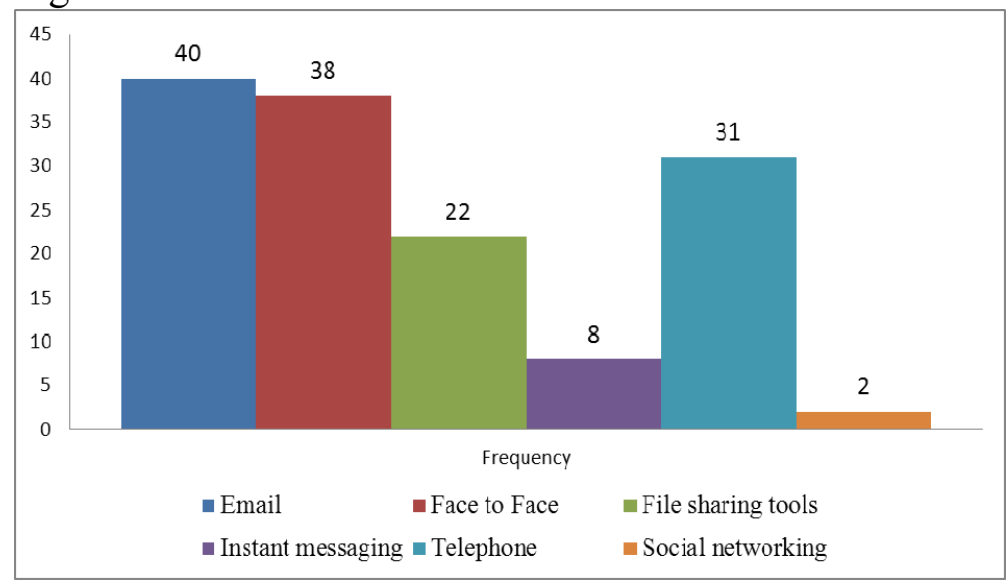




\section{Open ended questions}

Students' responses to open ended questions showed rich data for the study by describing different experiences that are situated within the same context of the design project. The open ended questions were designed to capture a snapshot of students' perceptions of their individual information behaviour and also their group behaviour as well. Data from open ended will be analyzed using a grounded theory approach with the necessary codes to understand the relationship between the learning task and the collaborative information behaviour. Some examples of students' responses to open ended questions:

Q. How would you describe your style of looking for information as a group for this project?

"Individual research, then group sharing, re delegation of research tasks, then more individual research" [Respondent D3]

"I need to write shorter answers, I'm hungry! As a group, we sit in the computer cluster together. We use Google and other search engines/database search (depends what we're each looking for) to find papers or articles or websites, keeping track of the sources. As we find information we want advice on or think would be relevant for our teammates, we discuss it immediately. We search for different topics, to make it more efficient." [Respondent I2]

Q. How would you describe your style of looking for information as an individual for this project?

"As an engineering student I want the most cutting edge information. I rarely look for information in print because I usually believe that there will be something more up to date on the internet. I look at print for fundamental engineering information, but when it comes to specifics it has to be the most recent. I guess my style would be use the internet, mostly the databases. First I will go to Wikipedia to get a broad understanding of the topic that will help me use the search engines more effectively. Then I use the databases provided by the engineering Library. I then look through patents using freepatentsonline.com. I try to look for standards, but usually only after they are mentioned in a paper." [Respondent A2]

"Split up very evenly between internet research and contacting companies and individuals who could be considered "specialists" in their respective fields" [Respondent $\mathrm{H} 2]$

\section{Discussion}

The results of this preliminary analysis show that student encounter different information-related activities during their project that are related to the stages of the project and these activities vary from individual ones to collaborative activities. The structure of groups along with individual interested was also detected as a factor to collaboration. 
Understating the variety of information sources that students would need and use for their project can help engineering librarians who are involved in such courses with knowing the commonly used sources that are not necessarily part of the library collections such as patents and technical reports.

The previous examples of students' answers to the open ended questions showed the richness of data that can capture the real world of students' experience, for example, students do not use Wikipedia as a reference in their reports but it so obvious it is part of their information-seeking process and it raises a challenge to know what information channels have been used during the process of information search and how they impacted learners' information behaviour. This will be clarified further in the second case study of this research through face to face interviews with students. The trend of engineering students to approach people as information channels was so obvious in many responses.

Conclusion and further steps

The previous analysis shows an overview of the research basic data about the course setting and students' conceptions of their collaborative information behaviour. Further descriptive analysis with findings will be performed in addition to an analysis of intra-group responses (responses from the same project group) and the variations among groups using more advanced statistical measures such as Analysis of Variance (ANOVA). The analysis will also help in identifying the categories of coding that will be used for analysing the collected qualitative data.

The purpose of this preliminary data analysis is to find out if the questionnaire, as a selected method for case study helped the researcher in getting more insights from students' replies describing their information-related activities during the design project. The data showed similarity among students but also variations in how they collaboratively search and use information. The responses to open ended questions have also provided many additional indicators that were not considered during the study design such as: how a group could agree on the relevance of an information source to be used in the project, and visits as information channels as provided in many responses such as:

"Although the group may have resisted some of the advice their resources gave them, they soon realized that the advice was in actual fact extremely beneficial. When discussing the options available to the team with respect to hardware that could be useful for their designs, we thought about going physically to the part-suppliers to speak to experts in the field. The team initially thought that they could just as easily get the needed information from the internet, so no such trip was necessary. Finally, after not much success, the team decided to go to three different stores to speak to the employees and browse through the available merchandise. The progress that was made on the designs from that one trip was more than what had been achieved in multiple meetings." [Respondent M2]

The inductive analysis of students' responses in addition to analysis of some groups' deliverables will provide the necessary needed data to understand a complex phenomenon of the effect of the design project as the learning task on the collaborative information behaviour of students. The 
results will guide the design of the interviews in the second case study to collect further data especially the answers that were not possible to gather through the questionnaire and the deliverables. Another major finding from these preliminary data is that the interaction between the two dimensions of this study (the learners' information behaviour and the learning task) was clear in many responses but the levels of interaction will be further investigated by conducting interviews. It is important to mention that the presented data in this paper constitute a small portion of the collected data for this study as the research is still in progress.

Investigating information behaviour of engineering students is an area of research that engineering librarians are best suited to do and it will definitely guide the practice they do through direct instruction to the class, meeting with students, or by providing web-based solutions such as subject guides and learning modules. It is also an area that demonstrates faculty-librarian partnership in conducting research in the field of engineering education and can guide the practice of library instruction in engineering courses.

Bibliography:

1. Lowe, A., McMahon, C., \& Culley, S. (2004). Information access, storage and use by engineering designers- part 1. Engineering Designer, 30(2): 30-32.

2. Accreditation Board for Engineering and Technology (ABET) criteria for assessing engineering programs 2009-2010, available online at http://www.abet.org/

3. Engineers Canada, Canadian Accreditation Board, Accreditation Criteria and Procedures. Canadian Council of Professional Engineers, 2008. Available at: http://www.engineerscanada.ca/

4. Murphy, S. \& Saleh, N. Information literacy in CEAB's accreditation criteria: the hidden attribute, In Proceedings of the Sixth International Conference on Innovation and Practices in Engineering Design and Engineering Education, 2009. Hamilton, ON July 27-29, 2009.Avaialble at: http://hdl.handle.net/1974/5171

5. American College and Research Libraries, Science and Technology Section. Information Literacy Standards for Science and Technology, 2004. Available at: http://www.ala.org/ala/acrl/acrlstandards/infolitscitech.html

6. Limberg, L. \& Sundin, O. (2006). "Teaching information seeking: relating information literacy education to theories of information behaviour" Information Research, 12(1), paper 280. Available at: http://InformationR.net/ir/12-1/paper280.html

7. Kolmos, A. (2006). Future engineering skills, knowledge, and identity. In J. Christensen, A. L. B. Henriksen \& A. Kolmos (Eds.), Engineering science, skills, and bildung (pp. 165-185)

8. Poltrock, S., Grudin, J., Dumais, S., Fidel, R., Bruce, H., \& Pejtersen, A. M. (2003). Information seeking and sharing in design teams. Proceedings of the 2003 International ACM SIGGROUP Conference on Supporting Group Work, 239-247.

9. Hansen, P., \& Järvelin, K. (2005). Collaborative information retrieval in an information-intensive domain. Information Processing \& Management, 41(5): 1101-1119.

10. Talja, S., \& Hansen, P. (2006). Information sharing. In A. Spink \& C. Cole (Eds.), New Directions in Human Information Behavior (pp. 113-134). Dordrecht, Netherlands: Springer. 